\title{
st \\ Francis Bacon e as marés: a concepção da natureza e o mecanicismo
}

\author{
Pablo Rubén Marigonda
}

Esta breve introdução visa duas tarefas ao mesmo tempo: primeiro, informar sobre a época provável de composição e o lugar ocupado, no conjunto da obra de Francis Bacon (1561-1626), pelo pequeno tratado intitulado De fluxu et refluxu maris (Do fluxo e refluxo do mar); segundo, expor a solução que nele se apresenta para o problema das marés, mostrando tratar-se de uma solução que se alinha ao estilo mecanicista da primeira metade do século xvı em sua negação da possibilidade de uma ação a distância por parte da Lua, muito embora defenda uma tese geocêntrica e geoestática que se opõe ao copernicanismo.

A investigação de Bacon sobre as marés - o fluxo e refluxo das águas do mar -é um caso particularmente relevante, porque nos coloca de imediato fora de um conjunto bastante usual de objeções à contribuição de Bacon para o desenvolvimento da ciência moderna, objeções que tendem a considerá-lo como ideólogo da ciência nascente, propagandista da união entre a ciência e o poder, visionário elaborador de instituições científicas, desenvolvedor e proponente do novo método científico mas, ainda assim, um autor que não se debruça sobre objetos propriamente científicos, que definitivamente não faz ciência. Ora, as marés são, nesse sentido preciso, um caso a parte, pois, em seu curto ensaio, Bacon oferece um tratamento para um objeto científico que, em sua época, não tinha ainda uma explicação racionalmente aceitável e que mobilizava um amplo conjunto de conhecimentos ligados à navegação e aos navegantes: conhecimentos das estrelas, das terras e das costas, mas também de roldanas, velas e lastros, ventos e brisas, e também de canais, rios e correntezas. As marés mobilizam, assim, um amplo conjunto de conhecimentos astronômicos, mecânicos, geográficos e cartográficos, produzidos sob condições especiais de coleta, pois consiste, com efeito, em um amplo conjunto de relatos observacionais (que devem ser colocados na categoria de conhecimento observacional indireto), consignados nas estórias dos navegantes, que são o resultado de uma prática observacional desenvolvida sistematicamente, no momento em que Bacon escreve, por mais de um século. 
Apresento, por fim, as questões mais propriamente ligadas ao desenvolvimento histórico da "teoria das marés", com o objetivo de enquadrar a tentativa baconiana no conjunto das interpretações mecanicistas da primeira metade do século xvII, mas o texto, que é aqui publicado em bilingüe, é rico de conseqüências para a aferição, em um assunto científico relevante, da concepção de natureza de Bacon, a qual comparece explicitamente em nosso pequeno texto. Não tratarei aqui de outros assuntos relevantes postos pelo Defluxu, tais como a relação entre o "método proposto" por Bacon em obras de caráter metodológico, tais como o Novum organum, que fazem parte de sua filosofia indutiva, e o "método praticado" por ele na história natural, especialmente na investigação acerca das marés; ou ainda, a questão tão debatida do lugar que Bacon reserva para as hipóteses na investigação científica e o lugar que elas ocupam em sua investigação sobre as marés; questões para as quais se espera a atenção mais detida daqueles que se dedicam à interpretação de Bacon.

\section{Data de Gomposição e localizaçÃo na obra de Bacon}

Convém considerar de início que, em geral, as histórias das marés não dedicam atenção alguma à tentativa baconiana, como é o caso de Gillet (1998), e mesmo um estudo, que se propõe como objetivo "a reconstrução do longo processo que conduziu à formulação newtoniana” (Russo, 2003, p. 24), não se dá sequer o trabalho de citar Francis Bacon ou mesmo de arrolar o texto sobre as marés na bibliografia (afinal, trata-se, no mínimo, de um original de época sobre o assunto). ${ }^{1}$ Uma fortuna diferente tem nosso texto na história científica das marés escrita por Cartwright (1999), que dedica o início do capítulo sobre as teorias pré-newtonianas a William Gilbert e Francis Bacon. Lamentável e ironicamente, a exposição de página e meia das idéias contidas no texto sobre as marés contém um erro grosseiro de datação e de localização na obra de Bacon. Com efeito, Cartwright, que caracteriza Bacon como um "amateur da investigação científica” (o que o liga à visão standard de Bacon como ideólogo da nova ciência), toma o

\footnotetext{
1 Voltarei mais adiante à questão de por que Bacon é normalmente desconsiderado nas histórias que traçam uma linha reta entre Copérnico e Newton ou naquele tipo de historiografia que analisa o desenvolvimento da ciência retrospectivamente a partir daquele conhecimento (teoria, hipótese, sistema) que acabou sendo considerado como explicativo para um certo conjunto de fenômenos ou acontecimentos do mundo. Essa estratificação, enrijecimento de uma interpretação histórica, tem o inconveniente de ter grande dificuldade de acomodar aqueles esforços que se afastam da linha de desenvolvimento dominante. Como Bacon não aceita a cosmologia copernicana e como tampouco defende uma teoria que aceita a influência da Lua sobre as águas marinhas, sua posição parece muito desinteressante mesmo do ponto de vista histórico, não servindo, nos casos mais radicais como o de Russo (2003), nem mesmo como curiosidade histórica.
} 
texto sobre as marés como fazendo parte dos Essays (Ensaios) que, segundo o intérprete, foram "escritos em seus últimos anos [e que] cobrem um amplo leque de questões filosóficas, incluindo o conhecimento natural" (Cartwright, 1999, p. 26), datando o trabalho, sem qualquer outra explicação ou argumento, no ano de 1623 (Cartwright, 1999, p. 33, nota 2). Cartwright comete uma série de enganos: primeiro, porque os Ensaios não são uma obra tardia, mas uma obra inaugural de 1597, que teve outras duas edições em vida, em 1612 e em 1625, nas quais Bacon foi acrescentando ensaios; segundo, porque o tratado sobre as marés não faz parte dos Ensaios que, contrariamente ao que afirma Cartwright, não tratam de modo algum de assuntos de filosofia natural, mas de filosofia moral, e que parecem também corresponder, em grande medida, a um exercício literário (cf. Strachan, 1997, p. ix) $;^{2}$ terceiro, não é muito difícil mostrar a arbitrariedade da data proposta por Cartwright, pois em 1620, quando da publicação do Novum organum, Bacon retorna, nos parágrafos 36 e 4,6 do segundo livro, à questão das marés, em termos que mostram que nosso tratado é de redação bem anterior (cf. Mariconda, 2004, p. 795, nota 2).

Surpreendentemente, nosso texto não teve melhor sorte nas mãos dos especialistas da obra de Bacon. Assim, Ellis, na introdução ao texto na edição das obras de Bacon, sem fazer menção a qualquer outra obra do autor, afirma que "Bacon não menciona a teoria de Galileu no presente tratado, que foi, portanto, provavelmente escrito antes ou não muito depois de 1616" (Ellis, 1876, p. 243). Como se vê, o texto de Bacon é assim datado por não fazer referência ao Discorso del flusso e riflusso del mare (Discurso do fluxo e refluxo do mar), escrito por Galileu pouco antes da promulgação do édito de condenação de Copérnico em 1616 e que circulou em cópias manuscritas, das quais uma chegou até Bacon; texto de Galileu que é, em 1620, mencionado e criticado por Bacon no Novum organum.

Mesmo em um autor como Rossi, que escreveu uma obra importante sobre Bacon, não se encontra uma indicação clara da posição do tratado e de sua época de publicação. Na verdade, Rossi segue uma argumentação muito parecida àquela de Ellis, assentando-a, de sua parte, em uma referência na correspondência de Bacon e de Galileu, ${ }^{3}$ na qual se diz que Galileu, em seu discurso sobre as marés de 1616, estaria dando uma resposta ao texto de Bacon, de modo que isso permite datá-lo como sendo anterior a 1616 (cf. Rossi, 1989, p. 121-3). Diga-se, a bem da verdade, que Rossi, no contexto de

2 Com efeito, é assim que o público recebeu a obra e não era outra a intenção de seu autor. Cabe lembrar que os Ensaios alcançaram grande sucesso na Itália, tendo recebido uma primeira tradução italiana, publicada em Londres em 1618 e uma segunda tradução de Andrea Cioli, então secretário da grã-duquesa Cristina de Lorena, publicada em Florença (1619) e reimpressa em Milão (1620), Veneza (1621) e Bracciano (1621) (cf. Rossi, 1989, p. 122-3).

3 É interessante notar que exatamente a mesma evidência retirada da correspondência está referida por Drake no contexto de reconstrução biográfica da atividade de Galileu (cf. Drake, 1988, cap. 15, seção 2, p. 359-60). 
comparação entre Bacon e Galileu no qual se move, não extrai essa conclusão, que fica totalmente subentendida em sua argumentação; entretanto, isso em nada altera a verdade da conclusão de que para Rossi o De fluxu et refluxu maris foi escrito antes de 1616. De resto, seu desinteresse por um exame mais detido do texto faz parte do desinteresse geral refletido pelas histórias das ciências que citamos ao início.

É evidente que nem Ellis nem Rossi têm condição de posicionar o tratado de Bacon no interior de sua obra; afinal, "por que Bacon se interessa pelas marés?" e "que lugar é ocupado por essa investigação no conjunto das preocupações e da investigação baconianas?" são questões centrais para a inteligibilidade do texto, para reproduzir o contexto no qual o próprio texto de Bacon ganha sentido; entretanto, ela é fundamentalmente uma questão interna, que reclama um marco interno de análise. Como o texto é datado em função da possível relação entre os escritos de Bacon e de Galileu sobre as marés, e não em função do desenvolvimento, estrutura e unidade do pensamento de Bacon, as questões acima não são nem mesmo postas e em vão procura-se nesses intérpretes qualquer indicação sobre o corpo doutrinário ou sistemático a que o pequeno tratado das marés poderia pertencer.

Para ter uma indicação mais precisa da localização e data do texto de Bacon, foi preciso esperar pela edição de Graham Rees (1996) das obras de Bacon, na qual, com efeito, mostra-se que o De fluxu et refluxu maris compõe um conjunto de seis textos, que permaneceram inéditos durante a vida do autor e incompletos, em-

Figura 1. Francis Bacon (1561-1626), em pintura que retrata nosso personagem realizada por Paul van Somer. Através dos olhos do artista, vemos Lorde Verulamo, no momento do retrato, Lorde Chanceler da Inglaterra, no auge de seu poder.

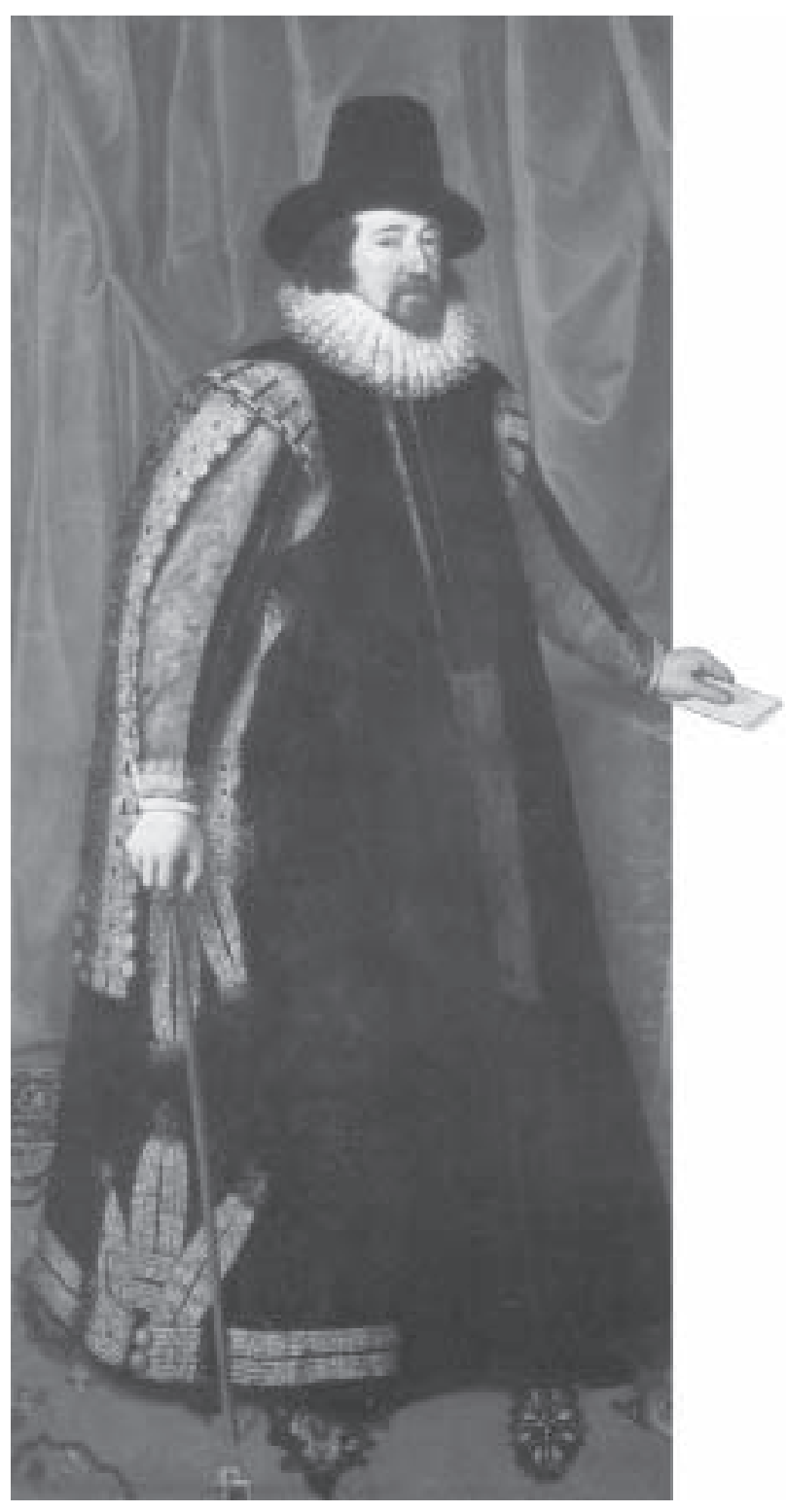


bora em etapas diferentes de elaboração e revisão, destinados a fazer parte do Instauratio magna (Grande instauração), obra programada para conduzir a uma completa reestruturação das ciências e dos ofícios humanos. O conjunto de ensaios foi escrito entre aproximadamente 1611 e 1619 e na seguinte ordem cronológica provável: (1) Phaenomena universi (Os fenômenos do universo), (2) De fluxu et refluxu maris (Do fluxo e refluxo do mar), (3) Descriptio globi intellectualis (Descrição do globo intelectual), (4) Thema coelis (Teoria do céu), (5) De principe atque originibus (Dos princípios e das origens) e (6) De vijs mortis (Dos caminhos da morte), dos quais os cinco primeiros foram publicados post mortem em 1653 e o sexto, que se achava perdido, só foi reencontrado em 1980 (cf. Rees, 1996a, p. xvii). Agora, diferentemente do que ocorria com Ellis e Rossi, o texto de Bacon sobre as marés passa a ter sua datação, caráter e função determinados com relação aos planos de composição da Instauratio magna.

As primeiras referências a essa seqüência de seis textos encontram-se em três fragmentos: "escritos no período de aproximadamente 1607 a 1611, esses fragmentos esboçam um plano de seis livros, que se transforma por volta de 1612 no plano de seis partes, descrito, por sua vez, cerca de oito anos mais tarde no Distributio operis de 1620 " (Rees, 1996a, p. xvii). Com isso, Rees acaba chegando a sua hipótese interpretativa básica (que se constitui num verdadeiro princípio hermenêutico), segundo a qual é altamente provável "supor que todo trabalho de filosofia natural escrito depois de 1607 foi produzido para o plano dos seis livros ou das seis partes" (Rees, 1996a, p. xix). Isto é suficiente para o propósito que temos aqui de localizar o texto de Bacon e mostra a importância de ter uma hipótese interpretativa interna para a reconstrução do significado e alcance do texto baconiano. Além disso, essa melhoria na inteligibilidade interna do texto auxilia na compreensão de seu lugar no esforço de chegar ao entendimento e à explicação das marés.

Posto, desse modo, que o texto sobre as marés pertence a um conjunto de trabalhos destinados a fazer parte de uma obra que se propunha produzir uma completa reestruturação dos conhecimentos humanos, a determinação de sua data provável de composição se dá pela relação que nosso texto mantém com os outros textos da série. Assim, Rees mostra que, dos seis textos, aquele cuja data de composição pode ser mais acuradamente determinada é a Descrição do globo intelectual, em virtude de uma referência interna ao texto bastante precisa, a saber a observação de Bacon de que a estrela nova de Cygnus dura já "duodecim annos integros" (doze anos inteiros)" (cf. Rees, 1996, p. xix-xx, nota 11); ora, como a estrela foi observada pela primeira vez em 1600, isso põe a escrita do texto da Descrição em 1612. Rees mostra a seguir que o Teoria do céu, "um ensaio de cosmologia e astronomia, e um documento de grande importância para um entendimento da filosofia natural substantiva de Bacon, propõe respostas especulativas a algumas das principais questões levantadas na Descrição" (Rees, 1996a, p. xxii). 
Essa conexão entre o Teoria do céu e a parte astronômica da Descrição põe a redação do primeiro texto imediatamente após a redação do segundo e praticamente na mesma data de 1612 .

Ora, o De fluxu et refluxu maris, nosso pequeno ensaio sobre o movimento das marés, trata particularmente das causas do ciclo de seis horas observado no movimento do mar, um movimento que Bacon associava com um dos principais assuntos do Teoria do céu - a saber, com o movimento diurno dos céus. Mas além dessa relação temática importante, Bacon alude no Do fluxo ao Teoria do céu, o que põe como provável que o primeiro foi escrito antes do segundo. Além disso, "evidência circunstancial ligando o De fluxu ao Thema e ao Descriptio sugere que o primeiro não pode ter sido escrito muito antes dos outros dois. Somente no Thema e no De fluxu, Bacon refere-se a sua teoria da verticidade; e somente no Descriptio e no De fluxu, ele faz um uso extenso de materiais retirados do Nova de universis philosophia (Nova filosofia do universo) de Patrizi" (Rees, 1996a, p. xxiv). Todas essas evidências permitem que Rees chegue finalmente a datar o De fluxu como tendo sido escrito "por volta do final de 1611" (Rees, 1996a, p. xxv). E novamente, após ter discutido toda a série dos seis textos, Rees sumariza suas conclusões para o caso de nosso texto, afirmando tratar-se "provavelmente de uma contribuição ou à Parte I ou à Parte v do Instauratio. Não é possível que tenha sido escrito depois de 1618 e quase certamente foi escrito circa 1611" (Rees, 1996, p. xxxv).4

A determinação da data de composição e escrita do texto é importante seja para posicioná-lo no interior do projeto filosófico baconiano, dando sentido às suposições que nele são feitas, no quadro de suas propostas para a história natural e a filosofia indutiva, seja para dar uma dimensão mais clara da relação de Bacon com os acontecimentos científicos de sua época, em particular, com a campanha galileana em favor do copernicanismo. Neste último aspecto, o texto sobre as marés é notável pelo esforço que se nota em Bacon por manter-se informado sobre os desenvolvimentos científicos recentes e sobre o debate acerca do copernicanismo. Ambos aspectos servem de fundo para a perspectiva analítica empreendida aqui, de posicionar a explicação baconiana no quadro das tentativas mecanicistas, apesar de seu claro afastamento com relação à concepção copernicana. Podemos concluir que as marés ocupam um lugar bem determinado nas preocupações de Bacon no período que vai de 1611, data provável de escrita do De fluxu, até 1620, com a publicação do Novum organum.

4. Esta data concorda com aquela atribuída ao tratado em Mariconda, 1999, p. 45. 


\section{A GONGEPÇÃo DE NATUREZA E O MEGANiGismo}

O aspecto mais notável da tentativa baconiana de explicação das marés encontra-se, sem dúvida, em sua recusa, formulada logo no início do texto, da "conjectura ligeira" de uma correspondência estrita ou causalmente eficiente entre o movimento da Lua e o movimento de fluxo e refluxo do mar. Essa recusa de aceitar qualquer tipo de influência ou ação a distância da Lua sobre as águas marinhas é tanto mais surpreendente quando consideramos que, durante todo o século xvi, com o advento e desenvolvimento das grandes navegações marítimas, tornaram-se sempre mais freqüentes as viagens e as rotas marinhas, o que permitiu a acumulação de uma significativa quantidade de observações em apoio da "doutrina lunar", 5 isto é, de uma vinculação, certa e necessária, entre a Lua e as marés. Esses dados mostravam que as marés altas (os fluxos) não só pareciam estar ligadas à passagem da Lua pelo meridiano local, mas também mostravam um atraso diário equivalente àquele pelo qual a Lua passa pelo meridiano (cf. Mariconda, 2004, p, 798, nota 10). Bacon, no De fluxu, aceita os dados observacionais que apontam para uma correlação constante entre o aumento e a diminuição das águas (magnitude da maré) e o tempo (período, ou seja, o intervalo temporal entre uma maré cheia e uma maré baixa) de suas reciprocações com a passagem e as fases da Lua, assim como aceita também a correlação entre a passagem do Sol pelos equinócios e as marés cheias dessas épocas. Contudo, Bacon rejeita a interpretação (interpretatio) qualitativa dessa correlação, negando qualidades e operações ocultas; o que se revela como uma "recusa de qualquer doutrina das marés que faça referência à 'atração' ['afinidade', 'simpatia'] entre a massa das águas e a Lua” (Rossi, 1989, p. 129). Sua atitude com relação à "doutrina lunar" é de simplesmente descartá-la como expressão de uma abordagem enganosa da relação entre o homem e a natureza, como fruto de uma mentalidade "supersticiosa". Assim, Bacon, no nosso texto, não só refuta a tese segundo a qual "os movimentos da Lua ou do Sol são postos como causa dos movimentos inferiores que lhe são análogos ou que o Sol e a Lua (como vulgarmente se diz) têm domínio sobre aqueles movimentos do mar" (p. $5^{31}$ ), mas procura desqualificar, de modo definitivo, a "doutrina lunar", mostrando suas origens psicológicas e religiosas: "cogitações desse tipo facilmente penetrem nas mentes dos homens em virtude da veneração dos corpos celestes" (p. $5^{31}$ ). Bacon refuta, então, energicamente a admissão - que lhe parece ocultista e astrológica - de um "consenso monádico e solitário"

5 A "doutrina lunar" é uma referência a Francesco Patrizi (1529-1597), que, no Nova filosofia do universo (1591), obra que serve de fonte para Bacon, desenvolve uma teoria da simpatia entre a Lua e as águas marinhas, pela qual a Lua provoca a distância, por afinidade, uma febre das águas marinhas que, por isso, se elevam (cf. Rossi, 1989; Rees, 1996b). 
na Terra, os ventos e as marés e, no Céu, o movimento diurno, que é tomado como sendo cósmico. Agora, para entender o significado da hipótese baconiana é preciso estar atento para o que ele entende por natureza.

E com efeito, Bacon, ao investigar a causa ou o "consenso das coisas" que origina o fluxo e refluxo, recusa a correspondência causal efetiva entre a Lua e as marés, pois afirma que não se segue da correspondência observada entre a Lua e as marés "que foram subordinadas pela natureza e que uma tenha a outra como causa" (p. $5^{31}$ ); o que significa que a natureza não está regida por um consenso (concordância) de tipo causal eficiente nem tampouco por uma "subordinação por natureza" (aparentemente, significando algo que se pudesse tomar como a definição desses acontecimentos naturais, digamos, a causa material e formal). Contra a pretensão causalista da explicação qualitativa da correspondência observada entre a Lua e as marés, Bacon levanta o fato também observado de que as marés são altas nos novilúnios e plenilúnios, "padecem as mesmas coisas, embora a Lua padeça coisas contrárias" (p. 531); o que é, por um lado, suficiente para destruir "tais fantasias de dominação", conduzindo, por outro lado, à conclusão, na qual Bacon expressa sua concepção de natureza, segundo a qual:

aqueles consensos [entre a Lua e o Sol e as marés] surgiriam das paixões universais da matéria e das primeiras conjunções das coisas, não como se um fosse regido pelo outro, mas porque cada um emanaria das mesmas origens e de causas comuns. (...) a natureza se compraz com o consenso, quase nunca admite alguma coisa única ou solitária (p. $\left.5^{31}\right)$.

Contra toda tentativa de estabelecer influências ocultas e consensos entre fenômenos isolados, Bacon opõe a concepção de que os acontecimentos naturais estão regidos por um consenso universal, uma espécie de concordância harmoniosa entre os acontecimentos naturais, decorrente de terem as mesmas origens e causas comuns. Note-se, entretanto, que "a natureza se compraz com o consenso", com o que Bacon reafirma "a idéia de uma regularidade e solidariedade [universais] entre os fenômenos naturais" (Rossi, 1989, p. 130). O consenso corresponde assim a uma espécie de concordância harmoniosa entre o todo e as partes, onde cada parte está ordenada em função do todo e concorre para a manutenção do todo. Trata-se, com efeito, da procura por uma outra espécie de causalidade, atenta para as concordâncias funcionais e genéticas (de origem).

A conseqüência da não aceitação da "doutrina lunar" de Patrizi e da adesão à concepção da natureza entendida como consenso (concordância) universal, é que Bacon, assim como Galileu, procura "uma solução para o problema das marés exclusivamente em termos de movimentos e composições de movimentos (...), movendo-se no plano 
do mais intransigente mecanicismo" (Rossi, 1989, p.128). A recusa da teoria dos influxos lunares alinha-se, assim, à procura por uma explicação mecânica, abrindo a possibilidade de uma física mecanicista. Paradoxalmente, apesar de afastar-se da cosmologia e da astronomia copernicanas, Bacon mantém-se no espírito de sua época, ao procurar por uma solução mecanicista, que se expressa na hipótese geral que associa $o$ movimento das marés ao movimento diurno dos céus.

Cabe considerar relativamente à tese do movimento diurno dos céus, que Bacon desenvolve uma visão cosmológica geocêntrica e geoestática, de modo que, para ele, o movimento diurno que se observa fazerem os corpos celestes - planetas e estrelas - de oriente (leste) para ocidente (oeste) é, tal como na cosmologia de Aristóteles, um movimento real. Entretanto, para Bacon, esse movimento de rotação perpétua, que realiza uma rotação completa em 24 , horas, não é apenas celeste, de modo que não se detém na esfera lunar, mas é antes cósmico, ou seja, está presente desde a sumidade do céu, nas estrelas fixas, até o ar e a água da Terra. A velocidade desse movimento cósmico diminui progressiva e regularmente à medida que se aproxima do globo terrestre imóvel, de modo que o movimento é máximo no caso da esfera das estrelas fixas e decresce continuamente da esfera de Saturno até a esfera da Lua, para tornar-se mínimo no caso do ar e do oceano. ${ }^{6}$ Em suma, as águas e o ar participam do movimento do primeiro móvel, que move o universo inteiro até a superfície da Terra, com exceção de seu interior, produzindo, no ar e na água, uma corrente que se desloca lenta e constantemente de oriente para ocidente.

Também aqui, para justificar que o movimento diurno não pára na esfera da Lua, mas continuaria operativo no ar e na água terrestres, Bacon lança mão de sua concepção de natureza, afirmando que "não é verossímil que a natureza deixe subitamente de lado um tal consenso [o do movimento diurno], que continua por tanta extensão e que se repõe gradativamente" (p. 533). Bacon supõe, portanto, um princípio de ordenação tal que o movimento é máximo para as estrelas, diminui gradativamente para os planetas a partir de Saturno, tornando-se mínimo para o ar e a água, mas suficiente ainda para imprimir-lhes um movimento contínuo de oriente (leste) para ocidente (oeste).

Convém, entretanto, considerar que o movimento recíproco do fluxo e refluxo do mar, que constitui propriamente o que se denomina maré, possui, na concepção de Bacon, um caráter derivado, pois, com efeito, na ausência dos continentes, tudo o que

\footnotetext{
6 A hipótese geocêntrica baconiana é obviamente contrária ao princípio de ordenação heliocêntrico, exposto por Copérnico na Dedicatória ao papa Paulo V do De revolutionibus, segundo o qual quanto mais próximo um planeta está do Sol mais rápida é sua translação e quanto mais afastado do Sol, mais lenta. O princípio copernicano visa mostrar a monstruosidade do princípio de ordenação geocêntrico, que deve considerar que as estrelas realizam sua rotação diária em 24, horas com velocidade altíssima, enquanto Saturno percorre sua órbita própria com velocidade lentíssima. Bacon silencia completamente sobre estas dificuldades e complicações no De fluxu.
} 


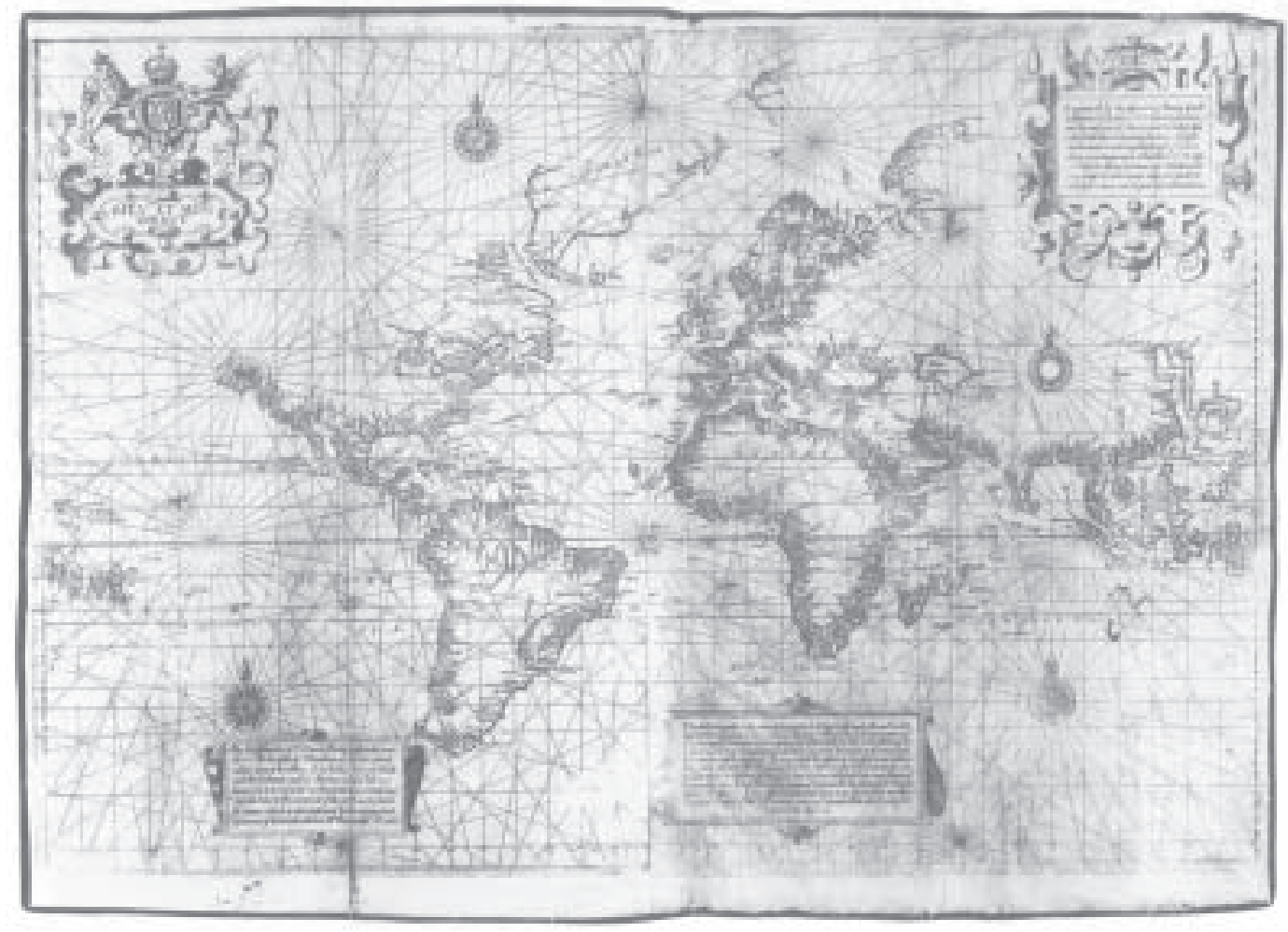

Figura 3. Mapamundi de Edward Wright, Londres, 1599. Este mapa, extraordinário em sua execução, marca $o$ avanço da cartografia inglesa, combinando a projeção de Mercator e o estilo portulano das rosas dos ventos. Os últimos descobrimentos estão marcados por três grandes quadros e ainda se nota a insistência em escrever os nomes dos lugares em posição perpendicular à costa, o que lhe dá um ar antiquado.

se teria é a simples presença de uma corrente contínua em direção ao poente, ou seja, ao ocidente. É, portanto, a interrupção da corrente pelos continentes o que causa o fluxo e refluxo do mar (cf. Cartwright, 1999, p. 27-8; Rossi, 1989, p. 127). Supondo-se, então, o que corresponde esquematicamente à situação geográfica real, que a imensa mole de água oceânica seja dividida por dois grandes continentes dispostos no sentido norte-sul, a saber, a América, o Novo Mundo, de um lado, e a Europa, Ásia e África, o Velho Mundo, de outro, entre os quais se estendem dois grandes oceanos - o Atlântico e o Pacífico-, pode-se concluir, segundo Bacon, que

esses dois obstáculos insinuem e comuniquem a natureza da dupla reciprocação universal pela imensa mole de água e se produza no quadrante do movimento diurno, de modo que, como as águas são evidentemente refreadas de ambos os 
lados, o fluxo e o refluxo do mar espalha-se duas vezes ao dia, certamente em períodos de seis horas, já que duplo é o avanço e, do mesmo modo, dupla a repercussão (p. 543).

Assim, embora Bacon não aderisse às posições copernicanas com Gilbert e Galileu, evidentemente compartilhava, particularmente com este último, a convicção (crença) de que a relação entre a maré e a passagem da Lua pelo meridiano do lugar era uma mera coincidência, sendo que a periodicidade (regularidade) observada é devida, em Bacon, ao efeito mecânico de percussão das águas marinhas contras as costas continentais interpostas, em virtude do consenso das águas com o movimento cósmico de 24 horas sobre os pólos norte e sul da Terra, com seu interior imóvel no centro do universo.

\section{Estrutura e conteúdo do "De fluXu et refluxu maris"}

O objetivo desta parte é expor sumariamente a estrutura e o conteúdo do discurso baconiano sobre as marés, que está composto por cinco partes, segundo o que segue:

(1) Parte introdutória (p.521-5), na qual (1a) afasta de saída a "hipótese da Lua", de que o movimento das marés possui uma correlação eficiente com os movimentos da Lua; o que é considerado por Bacon como o resultado de uma "conjectura ligeira" e (1b) apresenta os cinco movimentos observados do mar, dos quais o primeiro, que corresponde às correntes, é tomado por Bacon como irregular, e os demais quatro - a saber, o movimento diário de seis horas, o movimento mensal de restituição do diário, o movimento quinzenal de incremento das marés nos novilúnios (Lua nova) e plenilúnios (Lua cheia) e o movimento semestral de incremento das marés nos equinócios são regulares. Apresentada a classificação, Bacon (1c) afasta as correntes, basicamente devido a seu movimento irregular, procurando mostrar, apoiado em Patrizi, como as correntes alteram e podem até mesmo ocultar o movimento universal e regular do mar. Eliminadas as correntes, (1d) mostra que o movimento que se trata de explicar é o de seis horas do fluxo e refluxo do mar, já que os outros três só restituem os períodos mensal e anual ou amplificam os efeitos do movimento universal das seis horas.

(2) A segunda parte (que se estende da p. 525 à 529 do texto) corresponde à primeira investigação que está voltada para uma análise dos quatro movimentos regulares do mar e de suas dependências mútuas. Assim, Bacon (2a) apresenta, primeiramente, os argumentos para o estabelecimento de que o movimento das seis horas de fluxo e refluxo é o que se chama de "movimento próprio" do mar, sendo os outros três subordinados, pois não existiriam sem o primeiro; (2b) faz uma longa discussão (p. 525-9) 
sobre duas hipóteses acerca do modo pelo qual acontece o movimento de 6 horas das águas marinhas, a saber, a hipótese qualitativa de Francesco Patrizi, segundo a qual esse movimento é de inchaço das águas, produzido por uma espécie de "simpatia" entre as águas marinhas e a Lua; e a hipótese mecânica, segundo a qual o movimento de fluxo e refluxo é um movimento progressivo de deslocamento das águas. Bacon argumenta decididamente em favor da hipótese de que as marés são um efeito mecânico da propagação das águas e de seu impacto nos continentes de terra.

(3) A terceira parte (p. 529-33) está claramente constituída pela investigação acerca da causa ou consenso pelo qual agem as águas no movimento das 6 horas. (3a) Bacon inicia a investigação retornando à recusa da explicação em termos da influência dos corpos celestes sobre as águas marinhas, apesar das correlações observadas parecerem indicar o contrário, para justificá-la com base em sua concepção da natureza (da qual tratamos no item 2); (3b) apresenta a seguir o movimento diurno do céu para propor a convicção antecipatória ("enraizou-se profundamente em nós, quase como um oráculo"), mais simplesmente, a conjectura ou a hipótese de que o movimento progressivo de seis horas das águas marinhas é do mesmo gênero que (está em consenso com) o movimento diurno, ou seja, nos termos da concepção de natureza de Bacon, de que há um consenso universal entre o movimento das marés e o movimento diurno cósmico, no sentido de que este último representa para as coisas naturais a mesma origem e causa comum.

(4) Bacon investiga, na quarta parte (p. 533-43), as dificuldades envolvidas na suposição de que há um consenso entre as águas marinhas e o movimento diurno dos céus, desdobrando essas dificuldades segundo as três seguintes linhas investigativas:

(4a) A primeira investigação (p. 533-5) visa estabelecer o caráter cósmico (absolutamente universal no sentido de que se aplica rigorosamente a todas as coisas que estão no mundo) do movimento diurno. Com sua argumentação, Bacon visa garantir que o movimento de 24, horas não fique restrito ao céu, ou contido em seu limite, mas desça para baixo da região lunar, ${ }^{7}$ sendo, primeiro, "discernido evidentissimamente nos cometas pouco elevados que, embora sejam inferiores ao orbe lunar, no entanto, rodam evidentemente de oriente para ocidente" (p. 533); e depois, descoberto gradativamente no ar por meio dos relatos daqueles que navegam nos trópicos de que nestes

7 É interessante notar que, apesar de aderir ao geocentrismo, Bacon opõe-se, neste aspecto, à cosmologia tradicional ptolomaico-aristotélica, para a qual a esfera da Lua é o limite, a fronteira, entre as duas regiões, a celeste e a terrestre. Bacon está violando a distinção cosmológica fundamental que impõe uma visão do mundo como composto por duas regiões heterogêneas. Pode-se ver, em sua argumentação sobre o caráter cósmico do movimento diurno, uma tentativa de unificação da física e da astronomia e, seguramente, a aderência à tese da homogeneidade do universo, que se constitui em outro aspecto moderno da filosofia de Bacon. 
"sopra uma aura perpétua e perene de oriente para ocidente" (p. $5^{3} 5$ ). 0 argumento da primeira investigação contém, assim, duas partes: a formulação da hipótese geral de que o movimento diurno de 24 horas é um movimento cósmico; a evidência observacional favorável a essa hipótese concernente aos cometas e ao movimento do ar. Quanto à hipótese geral, da qual já falamos no item 2, cabe lembrar que afirmar o caráter cósmico do movimento diurno consiste em defender a tese de que esse movimento desce até a Terra com velocidade gradativamente diminuída, segundo a circulação do movimento de 24 horas, percorre círculos menores, até reduzir-se ao seu centro, que é a Terra, da qual o interior e a parte de terra da crosta está imóvel.

(4b) A segunda investigação (p. 535-41) visa estabelecer, por meio de três experimentos, a existência de um movimento perpétuo das águas marinhas de oriente para ocidente, isto é, na mesma direção do movimento diurno universal, de modo a obter a prova do consenso entre as águas e o movimento de 24 horas do dia e da noite. (4.br) O primeiro experimento $\left(p \cdot 5^{3} 5^{-}-\right.$) recolhe um conjunto de observações concernentes ao fluxo e refluxo do mar nas várias regiões e mares da Terra, com o objetivo de mostrar que, dada a situação geográfica do globo terrestre, no qual enormes massas de águas oceânicas estão separadas por dois continentes de terra - Europa-África-Ásia e América - que se estendem de norte para sul, e que deixam passagens em direção às extremidades (pólos) norte e sul, pode-se constatar nessas duas regiões, nas quais o oceano é um contínuo e não sofre interrupção, um movimento perpétuo e constante das águas de oriente para ocidente. (4.b2) O segundo experimento (p. $5^{3} 7^{-9}$ ) recolhe um conjunto de observações concernentes à diferença de horário (atraso da maré) ao longo da costa ocidental da África que Bacon supõe ser causada pela situação geográfica (existência de dois continentes dispostos no sentido norte-sul) e pela pressão das águas do oceano Índico que, ao moverem-se perpetuamente de oriente para ocidente, penetram pela abertura ao sul da África pressionando as águas do Atlântico para o norte, supõe-se que o mesmo deve ocorrer nas costas orientais da América, onde deveria ocorrer o mesmo tipo de progressividade da maré produzida pela pressão das águas do oceano Índico. (4,b3) O terceiro experimento (p. $5^{39}$ ) traz as observações concernentes ao comportamento das marés em golfos, em apoio da tese de que a intensidade dos fluxos e refluxos estaria na dependência da direção (de oriente para ocidente ou de ocidente para oriente) da inclinação do golfo, ou seja, de sua abertura, de modo que aqueles dirigidos (abertos) para ocidente possuem fluxos maiores que os dirigidos (abertos) para oriente.

Convém aqui comentar um aspecto epistemológico relevante desse uso que Bacon faz do termo experimentum, que é também revelador da concepção de experiência aqui empregada, porque os três experimentos que acabamos de expor são, na verdade, relatos (descrições) que resumem amplos conjuntos de observações, de conhe- 
cimentos geográficos e cartográficos, coletados por Patrizi, que Bacon utiliza como evidência empírica em favor de sua hipótese (antecipação). Trata-se, sem dúvida, de conhecimento observacional indireto. De qualquer modo, deparamo-nos aqui com a utilização, para fins de explicação das marés, do conhecimento geográfico recente e com a utilização de mapas que já incorporavam os avanços recentes nos métodos de projeção cartográfica.

Finalmente, Bacon aplica (p. 5411) os três experimentos na solução da segunda investigação, que consiste em afirmar a existência de um movimento perpétuo das águas marinhas em direção de ocidente causado pelo movimento de 24 horas de toda a máquina do mundo em torno da Terra, adaptando a suas necessidades a teoria da verticidade de William Gilbert (cf. Bacon, 1876, p. 263, nota 1; Rees, 1996a, p. lii-liii), para afirmar que o movimento cósmico universal não move a Terra, que fica estacionária no

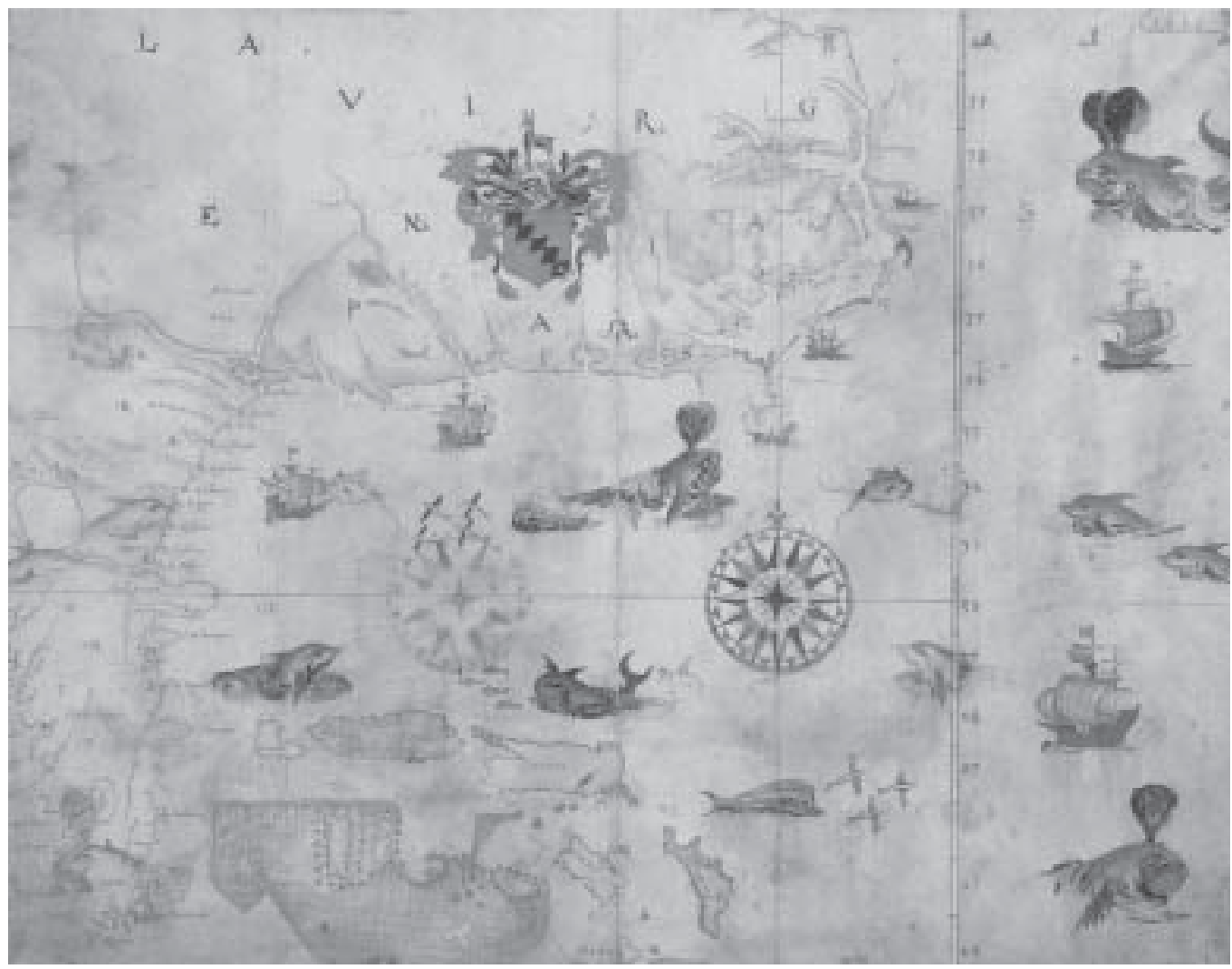

Figura 4. Mapa de parte da costa leste da América do Norte, produzido em ${ }_{5} 85$ por John White, no qual se representa desde a Flórida (abaixo à esquerda) até Outers Banks, com detalhamento do litoral, dos arrecifes e das ilhas. 


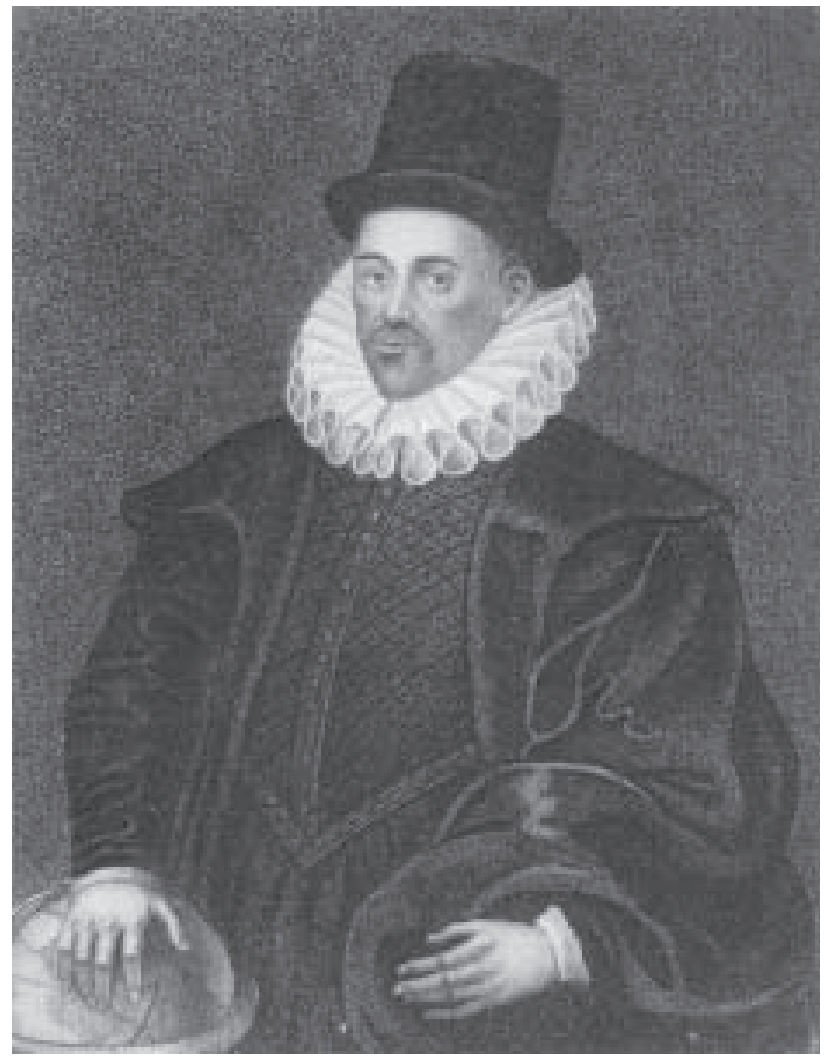

Figura 5. William Gilbert (1540-1603) foi médico da rainha Elizabeth I, da Inglaterra, e autor do influente De magnete, publicado em 1600, no qual desenvolve a filosofia magnética, que tem como uma das conseqüências a proposição de que a Terra gira sobre seu próprio eixo norte-sul, produzindo o dia e a noite, afirmação evidentemente contrária à hipótese baconiana do caráter cósmico do movimento diurno. centro imóvel da rotação, embora mova o ar e a água na direção de oriente para ocidente sobre o eixo constituído pelos pólos norte e sul da Terra. A teoria da verticidade é desenvolvida por Gilbert (1958), no capítulo 4 do Livro vi do De magnete, como parte da argumentação em favor do movimento de rotação da Terra em torno de seu eixo norte-sul; argumentação, portanto, em favor de uma hipótese diferente para o movimento diurno de 24 horas que a hipótese defendida aqui por Bacon. Em Gilbert, a idéia de verticidade é desenvolvida para dar solução a uma conseqüência indesejável de sua hipótese de que a Terra é um imenso magneto e, por isso, apresenta uma orientação magnética, que é compartilhada por todos os corpos celestes esféricos, de dirigir-se a partir do equador em ambas as direções, norte e sul, para os pólos, a saber, como explicar que os corpos da superfície da Terra possuem uma tendência para dirigir-se ao centro da Terra e não ao norte ou ao sul, dependendo do hemisfério em que se encontrem. Para Bacon, a verticidade é, como diz Rees (1996a, p. liii), "a forma mais atenuada do movimento diurno. Aqui como em outros lugares opera uma suposição importante: que dois estados antitéticos quaisquer im-

plicam geralmente um estado intermediário entre eles. Neste caso, é como se Bacon tomasse a verticidade como uma transição entre o movimento diurno em sua forma rotacional e a absoluta inatividade do interior da Terra".

(4c) a terceira investigação (p. 541-3) apresenta a solução de Bacon para a reciprocação de seis horas das marés, mostrando como ela coincide com o quadrante do movimento diurno com a diferença de 50 minutos diários correspondentes ao atraso da passagem da Lua pelo meridiano, em virtude de seu movimento de translação próprio, de modo que o ciclo mensal das marés acaba coincidindo com o mês lunar, não 
porque haja uma afinidade qualitativa entre a Lua e as águas marinhas, mas em virtude do consenso existente entre o movimento diurno e o movimento próprio dos planetas.

(5) Segue-se a quinta parte, na qual se apresentam (5a) as Investigações, (5b) as Restrições e (5c) as Conjunções. Esta parte final tem caráter claramente prospectivo e de controle pela experiência da hipótese proposta por Bacon.

(5a) Quanto aos mandata, cabe sem dúvida notar que se trata de um termo do vocabulário jurídico, transferido para o vocabulário metodológico. Com efeito, o termo latino mandatum vem do verbo mandare (mandar, ordenar) e expressa de modo geral uma incumbência, algo de que se está encarregado. O termo faz parte, desde os tempos romanos, do vocabulário jurídico, pois já em Cícero expressa encarregar alguém de uma comissão (representação) para alguém, que é o sentido usual de mandato judicial, no qual se concede poder a alguém para o desempenho (execução) de uma representação. Ora, em Bacon, essa incumbência é de fazer observações em regiões da Terra bastante afastadas entre si, de modo que é preciso que a parte que recebe a incumbência a aceite e proceda às observações de modo rigoroso, para que se possa realizar a tarefa metodológica de testar - confirmar ou infirmar - a hipótese proposta por Bacon para o movimento das marés.

(5) Quanto às Restrições, Bacon se mostra consciente de que falta explicar o consenso do ciclo mensal do mar com o mês lunar e, portanto, explicar a correlação entre o atraso diário do fluxo e o movimento da Lua.

(5c) Nas Conjunções, Bacon reconhece que a hipótese de que o movimento diurno de 24. horas é a causa das marés está em oposição à hipótese copernicana de que o movimento de 24, horas não é cósmico mas meramente um movimento de rotação da Terra sobre seu próprio eixo em 24 horas.

\section{Considerações finais}

Em vista do exposto acima, é possível considerar que Do fluxo e refluxo do mar representa um caso exemplar de como uma reflexão construída a partir da visão mágiconaturalista de Francesco Patrizi (1529-1597), tradicionalista no sentido de aderir inveteradamente à estabilidade da Terra e, portanto, do ponto de vista do desenvolvimento histórico das explicações das marés, descartável, por propor uma hipótese astronômica e cosmológica não alinhável ao desenvolvimento que conduziu à teoria newtoniana, pode, mesmo assim, integrar-se aos esforços de solução da época, alinhando-se ao seu tempo, seja por sua percepção central da necessidade de reforma do método científico e consciência de seu papel para o progresso do conhecimento, seja por sua adesão 
ao mecanicismo, à busca de uma explicação mecânica para as marés, ao invés das antecipações fáceis, "ligeiras", diz Bacon, de Patrizi, com sua hipótese qualitativa da febre causada pela Lua às águas marinhas, devido a uma empatia natural, que produziria um fervor vindo das profundezas das fossas marinhas e um conseqüente inchaço das águas, o qual se distribuiria depois como fluxo e refluxo.

O texto aqui publicado oferece, assim, ocasião de refletir sobre a dificuldade de considerar que Bacon busca por uma solução mecânica e, por extensão, alinhá-lo ao início da seqüência dos esforços mecanicistas que conduziram à explicação newtoniana que, como se sabe, responderá muito diferentemente de nosso autor, pois toma as marés como ocorrendo em uma Terra em movimento, causadas pela ação gravitacional exercida a distância pela Lua e pelo Sol sobre as massas oceânicas de água; o que não significa, entretanto, que a explicação de Patrizi esteja mais próxima da solução newtoniana que a malograda tentativa baconiana.

De todo modo, o texto sobre as marés também permite apreciar a confluência, particularmente em Bacon, entre duas vertentes normalmente separadas no desenvolvimento da ciência, a saber, a vertente que vem da matemática, que aplica a geometria ao conhecimento da natureza, que inventa a álgebra e o cálculo, e a vertente que vem da filosofia natural renascentista, hermética, naturalista, simbólica, que tem uma concepção mágica da natureza, nas qual as coisas naturais possuem qualidades e poderes ínsitos, ocultos e operativos (como se revela ainda na concepção alquímica da matéria como fonte de atividade).

Na teoria das marés de Bacon, confrontamo-nos com o nó vital da fundação da ciência moderna, com a profunda tensão que se revela existir no interior do movimento científico do século xviı entre a razão e a experiência, que parece colocar em campos opostos os racionalistas copernicanos - Kepler, Galileu, Mersenne, Descartes - que, sem negar a experiência, submetem-na à razão, impondo à natureza a regularidade e a legiformidade matemática, e a vertente naturalista fundada por Bacon, que segue tomando a experiência no sentido perceptivo mais imediato e opta por uma racionalização paripassu da experiência; o que leva ao longo caminho trilhado pela história natural, por ele concebida, da teologia natural à teoria evolucionista de Darwin que, não sem razão, declarava-se baconiano.

Pablo Rubén Mariconda Professor Titular de Filosofia da Ciência do Departamento de Filosofia da Universidade de São Paulo, Brasil. ariconda@usp.br 
Francis Bagon e as marés: a Gongepção dA NATUREZa e o meGanicismo

\section{REFERÊNGIAS BIBLIOGRÁFIGAS}

Bacon, F. De fluxu et refluxu maris. In: Spedding, J.; Ellis, R. L. \& Heath, D. D. (Ed.). The works of Francis Bacon. London: Longmans, 1876 .v. 3, p. $247^{-6} 7$.

De fluxu et refluxu maris. On the ebb and flow of the sea. In: REEs, G. (Ed.). Philosophical studies c. 1611-c. 1619. Oxford: Oxford Clarendon Press, 1996. p. 63-93. (The Oxford Francis Bacon, vi). Essays. London: Wordsworth, 1997.

Cartwright, D. E. Tides. A scientific history. Cambridge: Cambridge University Press, 1999.

Cassirer, E. Indivíduo y cosmos en la filosofía del renacimiento. Buenos Aires: Emecé, 1951.

Drake, S. Galileo. Uma biografia scientifica. Bologna: Mulino, 1988.

Ellis, R. L. Preface to the "De fluxu et refluxu maris". In: Spedding, J.; Ellis, R. L. \& Heath, D. D. (Ed.). The works of Francis Bacon. London: Longmans, 1876. v. 3, p. 235-45.

Galilei, G. Diálogo sobre os dois máximos sistemas do mundo ptolomaico e copernicano. Trad., introd. e notas de P. R. Mariconda. São Paulo: Discurso Editorial/Imprensa Oficial, 2004.

Gilbert, W. De magnete. Tradução de P. F. Mottelay. New York: Dover, $195^{8}$.

Gillet, A. Une histoire des marées. Paris: Belin, 1998.

Mariconda, P. R. Galileu e a teoria das marés. Cadernos de História e Filosofia da Ciência, 9, 1-2, p. 33-q1, 1999 .

. Notas da Quarta Jornada. In: Galilei, G. Diálogo sobre os dois máximos sistemas do mundo ptolomaico e copernicano. Trad., introd. e notas de P. R. Mariconda. São Paulo: Discurso Editorial/Imprensa Oficial, 2004. p. 792-841.

Rees, G. (Ed.). Philosophical studies c. 1611-c. 1619. Oxford: Oxford Clarendon Press, 1996. (The Oxford Francis Bacon, vI). Introduction. In: (Ed.). Philosophical studies c. 1611-c. 1619. Oxford: Oxford Clarendon Press, 1996a. p. xvii-cx. (The Oxford Francis Bacon, vI). .Commentary on "De fluxu et refluxu maris". In: (Ed.). Philosophical studies c. 1611-c. 1619 . Oxford: Oxford Clarendon Press, 1996b. p. 376-82. (The Oxford Francis Bacon, vI).

Rossi, P. La scienza e la filosofia dei moderni. Aspetti della revoluzione scientifica . Torino: Bollati Boringhieri, 1989.

. Bacone e Galilei: I venti, le maree, le ipotesi dell'astronomia. In: La scienza e la filosofia dei moderni. Aspetti della revoluzione scientifica. Torino: Bollati Boringhieri, 1989. p. 114- 58 .

Russo, L. Flussi e riflussi. Indagine sull'origine di uma teoria scientifica. Milano: Feltrinelli, 2003.

Spedding, J.; Ellis, R. L. \& Heath, D. D. (Ed.). The works of Francis Bacon. London: Longmans, 1876. v. 3. Strachan, J. Introduction. In: Bacon, F. Essays. London: Wordsworth, 1997. 